\title{
It is still mostly about the mitral valve
}

David P. Bichell, MD

See related article on pages 369-74.

Ginde and colleagues ${ }^{1}$ report laudable 30-year data following the repair of complete atrioventricular septal defect (CAVSD). This is among the longest series reported. Clearly, CAVSD is reparable in a durable and reproducible single operation for a great majority of patients, and this study adds confidence to that statement. Where problems emerge, they are likely the result of the mitral valve component, and a problematic mitral valve is responsible for a great majority of late morbidity and mortality following CAVSD repair. Improving our acumen in understanding which mitral valves are headed for trouble could be a fruitful target of focus to elevate the plateau of the survival curve out of the $80 \%$ range and closer to $100 \%$.

Much of the information reported from this and other longitudinal series are remarkably similar. Nearly all series draw Kaplan-Meier survival curves with an abrupt 1- to 2-year slide of early attrition, with an era-dependent depth of early slide, followed by a plateau at $70 \%$ to $80 \%$ for decades. ${ }^{2-5}$ Similarly superimposable are curves for freedom from important mitral insufficiency and from reoperation, which is usually for important mitral insufficiency. The reintervention curve flattens at $80 \%$ to $90 \%$ only after a slow decline that extends past the first decade (see Figure 1). Most series demonstrate an era effect, with significant survival improvements likely attributable to younger age at repair and improved myocardial protection in the current era. Most report current operative mortality of $3 \%{ }^{2,4,5}$

Mitral insufficiency figures prominently among causes for reintervention after CAVSD repair, and the need for reintervention is a predictor of late mortality. Ginde and colleagues ${ }^{1}$ note those patients requiring reintervention usually undergo reintervention early on, at a median interval of 1.1 years after initial repair. No significant procedural

\footnotetext{
From the Department of Pediatric Cardiac Surgery, Monroe Carell, Jr, Children's Hospital, Vanderbilt University, Nashville, Tenn.

Disclosures: Author has nothing to disclose with regard to commercial support.

Received for publication May 26, 2015; revisions received June 3, 2015; accepted for publication June 3, 2015.

Address for reprints: David P. Bichell, MD, Department of Pediatric Cardiac Surgery, Monroe Carell, Jr, Children's Hospital, Vanderbilt University, 5241 Doctor's Office Tower, 2200 Children's Way, Nashville, TN 37232-9292 (E-mail: david.bichell@ vanderbilt.edu)

J Thorac Cardiovasc Surg 2015;150:375-6

$0022-5223 / \$ 36.00$

Copyright (c) 2015 by The American Association for Thoracic Surgery http://dx.doi.org/10.1016/j.jtcvs.2015.06.020
}

predictors of residual or late mitral insufficiency are identified in the current series. There is not unanimity of opinion regarding whether patients who present with preoperative atrioventricular

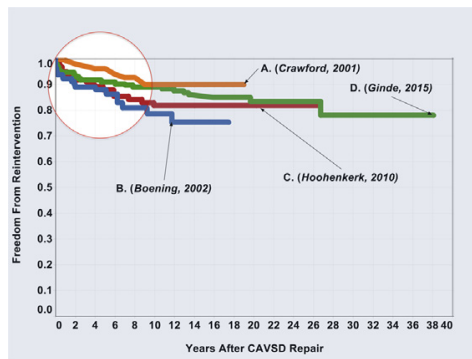
valve insufficiency are headed for trouble or for a straightforward course after repair. This same group formerly reported on a 20 -year experience with CAVSD and in that series demonstrated that preoperative moderate or even severe mitral insufficiency improved after CAVSD repair and was not a predictor of late mortality or reintervention. ${ }^{3}$ This finding is in contradiction to the findings in other large series where preoperative insufficiency is a predictor of morbidity or mortality. ${ }^{4,6}$ A majority of preoperative atrioventricular valve insufficiency in patients presenting with CAVSD may be a combination of mitral valve cleft, annular distortion, and unsupported bridging leaflet-all reparable in the course of a typical CAVSD correction. Standard corrections may render a majority of forms of preoperative mitral insufficiency irrelevant to the long-term outcome. However, within the population of patients with or even without preoperative valvular insufficiency lie treacherous, less common, usually subannular anatomic anomalies such as papillary asymmetry with hypoplastic commissures; double orifice mitral valve; or, perhaps most insidiously, other unrecognized chordal aberrations that may elude full preoperative characterization. These unrecognized variants may be just the patients who emerge from repair with mitral insufficiency, undergo repeated interventions by 1.1 years, and contribute to the slide from $97 \%$ early survival to $80 \%$ long-term survival.

The presence of early or late postrepair mitral insufficiency separates CAVSD patients into different strata of long-term risk. Careful analysis of the preoperative characteristics of this group might unmask some unrecognized subvalvular features that predict trouble after septation. Perhaps the most interesting subject of future analysis is this group of patients who constitute the slow slide in the reintervention curve over months to years after initial repair. Determining which CAVC valve variants will present intraoperative surprises at CAVC repair may permit the identification of anatomic subtypes that are better served by an alternate approach to the mitral valve component, by early mitral valve replacement, or even by transplant. 


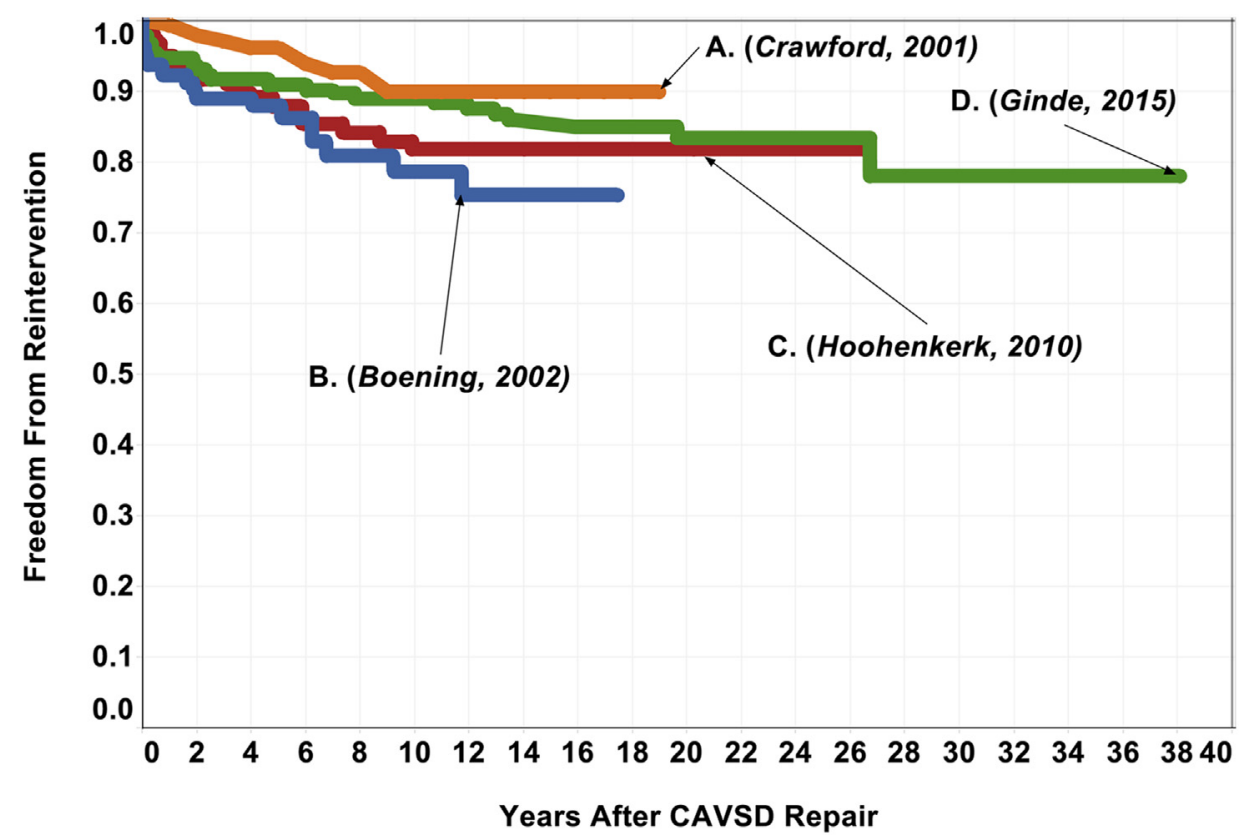

FIGURE 1. Composite graph of 4 studies, including the present study, showing Kaplan-Meier curves for freedom from reintervention or from important mitral insufficiency after repair of complete atrioventricular septal defect (CAVSD). ${ }^{1,2,4,5}$

\section{References}

1. Ginde S, Lam J, Hill GD, Cohen S, Woods RK, Mitchell ME, et al. Long-term outcomes after surgical repair of complete atrioventricular septal defect. J Thorac Cardiovasc Surg. 2015;150:369-74.

2. Boening A, Scheewe J, Heine K, Hedderich J, Regensburger D, Kramer HH, et al. Long-term results after surgical correction of atrioventricular septal defects. Eur J Cardiothorac Surg. 2002;22:167-73.

3. Tweddell JS, Litwin SB, Berger S, Friedberg DZ, Thomas JP, Frommelt PC, et al. Twenty-year experience with repair of complete atrioventricular septal defects. Ann Thorac Surg. 1996;62:419-24.
4. Hoohenkerk GJ, Bruggemans EF, Rijlaarsdam M, Schoof PH, Koolbergen DR, Hazekamp MG. More than 30 years' experience with surgical correction of atrioventricular septal defects. Ann Thorac Surg. 2010;90:1554-61.

5. Crawford FA Jr, Stroud MR. Surgical repair of complete atrioventricular septal defect. Ann Thorac Surg. 2001;72:1621-9.

6. Harkel Ten AD, Cromme-Dijkhuis AH, Heinerman BC, Hop WC, Bogers AJ Development of left atrioventricular valve regurgitation after correction of atrioventricular septal defect. Ann Thorac Surg. 2005;79:607-12.

7. Ando M, Takahashi Y. Variations of atrioventricular septal defects predisposing to regurgitation and stenosis. Ann Thorac Surg. 2010;90:614-21. 